\title{
Processos biológicos para o tratamento de efluentes: uma revisão integrativa
}

\section{Débora Carvalho da Silva Oliveira', Paulo Gabriel Ferreira de Azevedo ${ }^{1}$ e Luiz Antônio Pimentel Cavalcanti ${ }^{2}$}

\author{
${ }^{1}$ Instituto Federal de Educação, Ciência e Tecnologia da Bahia. Curso de Engenharia \\ Química. Campus Salvador. Rua Emídio dos Santos S/№. Bairro do Barbalho. \\ Salvador-BA, Brasil (CEP 40301-015). \\ ${ }^{2}$ Instituto Federal de Educação. Ciência e Tecnologia da Bahia. Campus Salvador. \\ Rua Emídio dos Santos S/№. Bairro de Barbalho. Salvador-BA, Brasil \\ (CEP 40301-015). E-mail: luiz.cavalcanti@ifba.edu.br.
}

\begin{abstract}
Resumo. 0 aumento das atividades industriais juntamente com um crescimento exponencial da população mundial, tem gerado grandes quantidades de efluentes contaminados por resíduos orgânicos, que costumam ser descartados nos corpos hídricos sem o devido tratamento, provocando a contaminação e poluição de rios e lagos. A fim de mitigar os impactos ambientais causados por esses lançamentos, os métodos de tratamento biológico, divididos em aeróbios e anaeróbios, têm sido amplamente estudados e empregados, apresentando resultados satisfatórios no tratamento das águas residuais. 0 presente trabalho traz uma revisão integrativa e apresentação de diversos resultados encontrados na literatura entre os anos de 2015 a 2021, indexados nas bases de dados Google Scholar, Scielo e Science Direct, através de descritores em português e inglês, sobre os processos de tratamento biológico. Foram utilizados 30 artigos e 24 trabalhos monográficos, referentes ao tema proposto. Dos quais, 18 artigos foram selecionados para a apresentação dos resultados durante a discussão. Os resultados encontrados neste estudo mostraram que as maiores eficiências do tratamento biológico foram evidenciadas nos sistemas em que os processos aeróbios e anaeróbios atuaram em conjunto.
\end{abstract}

Palavras-chave: Tratamento de efluentes; Processos anaeróbios; Processos aeróbios.

\begin{abstract}
Biological processes for the treatment of effluents: An integrative review. The increase in industrial activities coupled with an exponential growth of the world population, has generated large amounts of effluents contaminated by solid waste, which are usually discarded in water bodies without proper treatment, causing contamination and pollution of large environmental areas. In order to reduce the environmental impacts caused by these launches, biological treatment methods, divided into aerobic and anaerobic, have been extensively studied
\end{abstract}

Recebido

$21 / 03 / 2021$

Aceito

$15 / 04 / 2021$

Publicado

$30 / 04 / 2021$

Acesso aberto

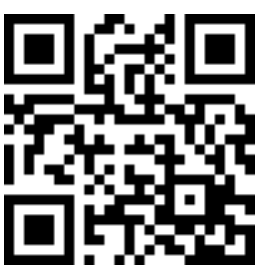

ORCID

(1) 0000-0003-0987-724X Débora Carvalho da Silva Oliveira

D) 0000-0003-0685-2928 Paulo Gabriel Ferreira de Azevedo

D 0000-0003-4932-9387 Luiz Antônio Pimentel Cavalcanti

ISSN 2359-1412/RBGAS-2021-0031/2021/8/18/26/397 
and used, with satisfactory results in the treatment of wastewater. The present work brings an integrative review and presentation of several results found in the literature between the years 2015 to 2021, indexed in the Google Scholar, Scielo and Science Direct databases, through the descriptors in portuguese and english, about the biological treatment processes. Thirty articles and 24 monographic works were used, referring to the proposed theme. Of which, 18 articles were selected to present the results during the discussion. The results found in this study showed that the greatest efficiencies of biological treatment were evidenced in the systems in which the aerobic and anaerobic processes acted together.

Keywords: Effluent treatment; Anaerobic processes; Aerobic processes.

\section{Introdução}

0 mundo vem acompanhando um crescente aumento das atividades industriais, provocando, segundo Santos et al. (2016), a contaminação e a poluição dos corpos hídricos, causados pelos lançamentos de efluentes indevidamente tratados nesses cursos. Em contrapartida, o aumento das ações fabris cresce juntamente com o da consciência pública em se estabelecer parâmetros para o lançamento de efluentes em meios naturais, bem como fomenta o estudo de técnicas e métodos que garantam o cumprimento desses parâmetros (Cornelli et al., 2014). No Brasil, esses parâmetros são normatizados pela Resolução CONAMA no 430/2011, (Brasil, 2011). Essa resolução descreve os limites permitidos de certas propriedades físicas e químicas do efluente, como $\mathrm{pH}$ e demanda química de oxigênio (DQO). Diante disso, observa-se a importância em se estudar métodos de tratamento de efluentes, visando o cumprimento das normas vigentes, bem como em se estabelecer atividades industriais cada vez mais ambientalmente amistosas (Azevedo et al., 2020).

Nesse sentido, surgem os tratamentos biológicos, que podem ser divididos entre aeróbios e anaeróbios. Segundo Aziz et al. (2019), esses dois tipos de tratamentos biológicos possuem suas vantagens e aplicações distintas. Para o aeróbio, os autores configuraram como sendo um método com alta eficiência de remoção de nutrientes do efluente, bem como sendo um processo mais rápido e menos sensível, permitindo estabelecer condições de processo menos rigorosas. Já o anaeróbio, de acordo com Aziz et al. (2019), é eficiente na remoção da matéria orgânica, menor produção de lodo, o que diminuiria as dificuldades do processo após o tratamento do efluente, requer menor energia, quando comparado com o aeróbio e, ainda, oferece a possibilidade de produção de biogás, que pode ser futuramente utilizado para produção de energia. Além disso, Silva et al. (2015) afirmam que a combinação desses dois tipos de métodos possibilita um sistema mais compacto, menor consumo de energia entre outros, tornando a pesquisa sobre o tema ainda mais importante para a eficiência do tratamento.

Diante da diversidade de aplicações e contextos para o uso dos métodos biológicos para tratamento de efluentes, o presente trabalho visa a fazer uma revisão bibliográfica integrativa sobre essas técnicas, explorando e analisando resultados da literatura especializada sobre o tema. 


\section{Metodologia}

0 presente artigo surgiu para traçar uma revisão integrativa sobre os principais métodos de tratamento biológico para tratamento de efluentes e seus processos. Com esse intuito, foram realizadas pesquisas na literatura especializada, com recorte temporal referentes aos anos de 2015 a 2021, relacionadas ao tema usando os descritores "tratamento de efluentes", "tratamentos biológicos", "tratamentos aeróbios", "tratamento anaeróbios", "wastewater treatment", "biological treatments", "aerobic treatments" e "anaerobic treatment" nas bases de dados Google Scholar, Scielo e Science Direct. Dentre os trabalhos encontrados, foram utilizados no presente estudo 30 artigos, sendo 10 anais de congresso, e 24 trabalhos monográficos. Dentre os artigos utilizados, apenas 18 foram selecionados para a apresentação dos resultados durante a discussão. Foram excluídos um total de 15 artigos, por fugirem do tema proposto, contabilizando um total de 45 artigos encontrados durante o período de busca. 0 critério de inclusão foi selecionar trabalhos que utilizassem apenas técnicas de tratamento biológico, bem como revisões bibliográficas, e como critério de exclusão os trabalhos que apresentavam métodos combinados biológicos, físicos e químicos, divergindo da temática proposta no presente estudo.

\section{Resultados e discussão}

Inicialmente foram identificados 45 artigos e 24 trabalhos monográficos nas bases de dados. Após a aplicação dos filtros, foram excluídos por leitura de título e resumo 15 artigos, que apresentavam métodos físicos e químicos combinados, não só biológicos, divergindo da temática proposta. Depois da leitura completa dos estudos elegíveis, 30 artigos atenderam aos critérios de elegibilidade deste estudo, sendo que 18 foram utilizados nos resultados. Os dados referentes à temática abordada nos estudos inclusos nos resultados, bem como o ano e nome dos autores estão especificados na Tabela 1.

0 tratamento aeróbio ocorre na presença de oxigênio e tem como objetivo a remoção da matéria orgânica presente no efluente através da ação de microrganismos aeróbios (Marcon, 2018). A degradação dos resíduos orgânicos ocorre por meio da digestão aeróbia, tal processo é favorecido pelo oxigênio dissolvido no meio e responsável pela oxidação dos compostos orgânicos, levando à formação de subprodutos como o lodo, gás carbônico e água, conforme apresentado na Equação 1 (Pompêo et al., 2015).

$$
\left.\mathrm{C}_{5} \mathrm{H}_{7} \mathrm{NO}_{2} \text { (células) }+7 \mathrm{O}_{2} \rightarrow 5 \mathrm{CO}_{2}+3 \mathrm{H}_{2} \mathrm{O}+\mathrm{NO}_{3}+\mathrm{H}+\quad \text { (Equação } 1\right)
$$

Nesse processo, as bactérias aeróbias decompõem o material orgânico complexo em material solúvel, que é absorvido pela parede celular e posteriormente utilizado como fonte de energia, favorecendo o aumento da massa bacteriana e gerando subprodutos (Pereira, 2015).

Os sistemas aeróbios são frequentemente utilizados em combinação com processos anaeróbios, a fim de obter uma maior eficiência no tratamento do efluente (Aziz et al., 2019). Estes dividem-se quanto ao tipo de aeração presente no sistema, podendo ser de forma natural ou forçada (realizada por aeradores mecânicos) (Lucena, 2016). Dentre os principais sistemas de tratamento aeróbio, destacam-se o sistema de lodos ativados, lagoas aeróbias (de alta taxa, facultativa, aerada e de maturação) e os filtros biológicos aeróbios (aerado submerso e percolador) (Salles, 2019). 
Tabela 1. Relação dos artigos inclusos e exclusos no estudo durante o período de busca.

\begin{tabular}{|c|c|}
\hline \multicolumn{2}{|l|}{ Artigos inclusos } \\
\hline Autor e data & Temática abordada \\
\hline Andrade et al. (2018) & $\begin{array}{l}\text { Análise da eficiência de um sistema composto por reator UASB e } \\
\text { filtros aerados no tratamento do esgoto de uma fábrica calçadista }\end{array}$ \\
\hline Baettker et al. (2018) & $\begin{array}{l}\text { Uso de materiais alternativos como meio suporte de filtros } \\
\text { anaeróbios no tratamento de esgoto sanitário }\end{array}$ \\
\hline Baettker et al. (2018) & $\begin{array}{l}\begin{array}{l}\text { Tratamento de lixiviados de aterros sanitários em lagoas } \\
\text { anaeróbias }\end{array} \\
\end{array}$ \\
\hline Baréa et al. (2019) & $\begin{array}{l}\text { Análise de um sistema composto por reator anaeróbio integrado } \\
\text { a lodo ativado no tratamento de esgoto sanitário }\end{array}$ \\
\hline Bezerra e Gonzalez (2020) & $\begin{array}{l}\text { Avaliação do desempenho de uma estação de tratamento de } \\
\text { esgoto composta por lagoa facultativa }\end{array}$ \\
\hline Carrilho e Carvalho (2016) & $\begin{array}{l}\text { Tratamento do lodo oriundo de fossa e tanque séptico em lagoas } \\
\text { de estabilização }\end{array}$ \\
\hline Cordero et al. (2015) & $\begin{array}{l}\text { Avaliação do desempenho de } 25 \text { estações de tratamento de } \\
\text { esgotos domésticos, formadas por lagoas de estabilização. }\end{array}$ \\
\hline Fernandes et al. (2015) & $\begin{array}{l}\text { Comparação entre três filtros anaeróbios preenchidos com } \\
\text { diferentes materiais filtrantes no tratamento de efluente de } \\
\text { tanque séptico }\end{array}$ \\
\hline Maia et al. (2015) & $\begin{array}{l}\text { Análise de um sistema composto por duas lagoas anaeróbias, } \\
\text { lodos ativados e uma lagoa facultativa no tratamento de lixiviado }\end{array}$ \\
\hline Medeiros et al. (2017) & $\begin{array}{l}\text { Comparação do desempenho de dois filtros biológicos } \\
\text { percoladores feitos com diferentes materiais alternativos }\end{array}$ \\
\hline Melo et al. (2018a) & $\begin{array}{l}\text { Análise da concentração de DBO em uma lagoa facultativa } \\
\text { empregada no tratamento de esgoto bruto }\end{array}$ \\
\hline Melo et al. (2018b) & $\begin{array}{l}\text { Análise da concentração de fósforo em uma lagoa facultativa } \\
\text { empregada no tratamento de esgoto bruto }\end{array}$ \\
\hline Monteiro et al. (2019) & $\begin{array}{l}\text { Avalição do desempenho de um sistema UASB e filtro biológico } \\
\text { percolador para o tratamento da mistura de lixiviado com esgoto } \\
\text { doméstico }\end{array}$ \\
\hline Nunes et al. (2019) & $\begin{array}{l}\text { Utilização de reator UASB e filtro biológico no tratamento de } \\
\text { esgoto doméstico }\end{array}$ \\
\hline Postigo et al. (2017) & $\begin{array}{l}\text { Análise da eficiência de uma fossa séptica destinada ao } \\
\text { saneamento rural }\end{array}$ \\
\hline Rocha et al. (2017) & $\begin{array}{l}\text { Comparação de diferentes combinações entre lodos ativados, } \\
\text { reatores UASB e filtro biológico percolador, no tratamento de } \\
\text { efluente de uma cervejaria artesanal }\end{array}$ \\
\hline Rodrigues et al. (2016) & $\begin{array}{l}\text { Desempenho de um sistema composto por reator UASB e filtro } \\
\text { anaeróbio no tratamento de efluentes de abate de frango }\end{array}$ \\
\hline Silva et al. (2018) & $\begin{array}{l}\text { Desempenho de um filtro anaeróbio de fluxo ascendente no } \\
\text { tratamento de efluente de suinocultura proveniente de reator } \\
\text { anaeróbio }\end{array}$ \\
\hline Total de artigos inclusos & Total de artigos excluídos \\
\hline 18 & 15 \\
\hline
\end{tabular}

O sistema de lodos ativados é mais frequentemente utilizado no tratamento de efluentes sanitários e industriais (Iopp e Mendes, 2020). É uma técnica indicada para efluentes que possuem uma alta taxa de contaminação por material orgânico e necessitam de um sistema de tratamento que não ocupe grandes áreas (Von Sperling, 2016). Nesse processo, a matéria orgânica é oxidada pelos microrganismos aeróbios e convertida em biomassa, que posteriormente é separada do efluente via sedimentação (Silva, 2018). Esse 
sistema é composto por um tanque de aeração e um decantador secundário (Von Sperling, 2016). No tanque de aeração ocorre a injeção de ar e a mistura do efluente com o lodo, que é rico em microrganismos aeróbios (Guedes, 2017). O lodo contido no tanque é formado, em sua maioria, por bactérias, fungos e protozoários, sendo as bactérias as principais responsáveis pela conversão dos resíduos orgânicos (Salles, 2019). 0 material orgânico presente no efluente é utilizado como fonte de alimento pelos microrganismos, que tendem a crescer e se aglomerar, dando origem aos flocos biológicos denominados de lodos ativados (Silva et al., 2015). O lodo ativado formado na primeira etapa é transferido para o decantador, onde é separado do efluente via sedimentação. 0 efluente tratado é descartado do decantador e a biomassa sedimentada passa por um processo de recirculação, onde é enviada novamente para o tanque de aeração, elevando a concentração de biomassa do sistema e aumentando sua eficiência (Von Sperling, 2016). 0 lodo produzido em excesso é retirado do tanque de decantação e destinado para tratamento específico (Pompêo et al., 2015).

A eficiência do tratamento por lodos ativados é garantida por um maior tempo de retenção da biomassa, equivalente a idade do lodo, o que permite que os microrganismos tenham tempo para metabolizar de $90 \%$ a $95 \%$ da matéria orgânica presente no efluente (Guedes, 2017; Salles, 2019). Apesar do maior consumo de energia elétrica, em comparação a outros tipos de tratamentos aeróbios, esse sistema costuma ser utilizado como tratamento secundário para efluentes de reatores anaeróbios, devido a sua alta eficiência na remoção da DBO total (Iopp e Mendes, 2020). Além disso, esse tipo de sistema também pode ser adaptado para realizar a desnitrificação e remoção de fósforo em certos tipos de efluentes (Von Sperling, 2016).

Com o intuito de analisar a eficiência de um sistema de tratamento composto por unidades anaeróbias e aeróbias, Baréa et al. (2019) estudaram o desempenho de um sistema composto por um reator anaeróbio integrado ao sistema de lodos ativados, sob a justificativa de diminuição da etapa de pós-tratamento, que é presente quando o tratamento ocorre puramente com reator anaeróbio. Para esse estudo, os autores utilizaram esgoto sanitário tratado por uma estação de tratamento de efluentes (ETE); sendo que o efluente segue para o reator após um tratamento prévio. $\mathrm{Na}$ análise dos valores para DBO e DQO do sistema completo, os autores obtiveram resultados de $64,1 \%$ e $55,1 \%$, respectivamente. Podendo-se concluir que essa combinação é eficiente no que diz respeito ao tratamento de efluentes.

Ainda no estudo da combinação de métodos anaeróbios e aeróbios, Rocha et al. (2017) compararam vários sistemas de tratamentos biológicos utilizando o dimensionamento de diferentes combinações entre os lodos ativados, reatores UASB e filtro biológico percolador, no tratamento de efluente de uma cervejaria artesanal, justificando que instalações que produzem cerveja geram resíduos líquidos ricos em matéria orgânica, que podem poluir reservas hídricas se indevidamente tratados. Para fins comparativos, os autores compararam os seguintes sistemas: dois sistemas de lodos ativados, reator UASB com filtro biológico percolador e o mesmo reator com lodos ativados. Segundo os autores, o melhor resultado foi encontrado para a combinação entre reator UASB com o sistema de lodos ativados, apresentando 97\% de eficiência na remoção da carga orgânica. Os resultados corroboram com o estudo realizado por Baréa et al. (2019). Dessa forma, esse trabalho mostra que o sistema de tratamento biológico composto por reatores UASB e lodos ativados são uma combinação eficiente de métodos anaeróbios e aeróbios para o tratamento de efluentes.

As lagoas aeróbias são sistemas de tratamento em que a degradação da matéria orgânica ocorre na presença de oxigênio, por meio de processos oxidativos. 0 fornecimento de oxigênio para a lagoa pode ser de forma natural, com a utilização de algas, ou de forma forçada, através de aeradores mecânicos. As unidades aeróbias costumam ser utilizadas de forma combinada entre si ou com outros processos, formando 
sistemas de estabilização, garantindo uma maior eficiência na remoção da matéria orgânica. Os principais sistemas de lagoas aeróbias são as de alta taxa, lagoas aeradas e lagoas facultativas (Lucena, 2016).

As lagoas de alta taxa consistem em tanques de tratamento compostos por algas e microrganismos aeróbios, responsáveis pela degradação da matéria orgânica através de processos oxidativos e fotossintetizantes (Ferreira e Seibert, 2016). O processo de remoção de poluentes acontece através da simbiose que a lagoa proporciona entre as algas e as bactérias (Lucena, 2016). As bactérias aeróbias presentes nas lagoas decompõem o material orgânico, formado na maioria das vezes por elementos complexos como proteínas e lipídios, transformando-os em dióxido de carbono e nutrientes que são essenciais para o funcionamento das algas (Carvalho, 2018). Os organismos fotossintetizantes possuem importante função no desempenho das lagoas, pois, além de produzirem o oxigênio utilizado pelas bactérias, também removem nutrientes como o nitrogênio e fósforo, que são incorporados nas algas, promovendo o decaimento da DBO do meio líquido. Desse modo, é essencial que as lagoas aeróbias sejam construídas com uma profundidade em que a energia luminosa consiga alcançar as algas que se encontram no fundo do tanque, possibilitando o processo de fotossíntese e aumentando o volume de biomassa algal por todo o corpo d'água (Lucena, 2016). Devido à grande turbidez da massa líquida encontrada na superfície da lagoa, que dificulta a entrada de luz, é necessário que essas unidades possuam pequenas profundidades (Ferreira e Seibert, 2016). As lagoas de alta taxa também possuem propulsores que proporcionam a movimentação da massa líquida, melhorando o contato do efluente com os microrganismos e possibilitando que todas as algas tenham acesso à luz solar. As lagoas aeróbias são indicadas para tratamento secundário de esgotos, devido à sua alta eficiência na remoção de DBO e fácil operação.

O sistema de lagoas facultativas convencional funciona de modo semelhante às lagoas de alta taxa, a partir da simbiose entre as algas e microrganismos. Essa unidade é composta por três zonas de tratamento: aeróbia, facultativa e anaeróbia (Gehling, 2017). Apesar desse sistema possuir uma zona anaeróbia, o efeito final do processo de tratamento é semelhante ao das lagoas unicamente aeróbias (Pellenz, 2018). A zona aeróbia é formada por algas e bactérias aeróbias, que decompõem o material orgânico através de processos oxidativos. A zona anaeróbia, que se encontra no fundo da lagoa, é caracterizada pela ausência de oxigênio e pela atividade bacteriana anaeróbia. Entre essas duas áreas encontra-se a zona facultativa, que é constituída por bactérias aeróbias e anaeróbias, responsáveis pela eliminação dos resíduos orgânicos dispersos no meio líquido (Sousa, 2018). A zona aeróbia é localizada na camada superior da lagoa facultativa, onde as algas recebem uma maior incidência de radiação solar, promovendo o processo fotossintetizante e a posterior produção de oxigênio. As bactérias aeróbias alojam-se na superfície e utilizam o oxigênio formado para realizar a degradação do material orgânico em suspensão, liberando gás carbônico durante o processo (Pellenz, 2018). Os sólidos em suspensão não solúveis se depositam no fundo da lagoa, formando lodo. Essa área é restrita de iluminação, o que prejudica o desenvolvimento das algas, provocando o decaimento do oxigênio dissolvido no meio (Gehling, 2017). A falta de oxigênio no fundo da lagoa promove a ação das bactérias anaeróbias, que convertem a matéria orgânica presente no lodo em $\mathrm{CO}_{2}$, metano, dentre outros gases (Sousa, 2018). A incidência de luz tende a diminuir conforme o aumento da profundidade da lagoa, dificultando os processos de fotossíntese e respiração aeróbia. A zona facultativa pode ser entendida como uma camada intermediária entre a zona aeróbia e anaeróbia, onde a quantidade de oxigênio dissolvido varia durante determinados períodos do dia, devido à baixa incidência de luz (Gehling, 2017). A variação do oxigênio dissolvido nesta área possibilita tanto a ação das bactérias aeróbias, quando há presença de $\mathrm{O}_{2}$, quanto a atuação das bactérias anaeróbias, na ausência de oxigênio (Sousa, 2018). 
As lagoas facultativas podem ser do tipo convencional ou aeradas. Ambas possuem o mesmo processo de tratamento, diferindo apenas no tipo de aeração. Nas lagoas convencionais o oxigênio dissolvido no meio é produzido através da fotossíntese realizada pelas algas, enquanto que nas aeradas o oxigênio é fornecido por aeradores mecânicos, havendo apenas as zonas aeróbias e anaeróbias (Salles, 2019). As lagoas facultativas possuem uma alta eficiência na remoção da $\mathrm{DBO}_{5}$, entre $70 \%$ e $90 \%$ (Henares, 2015), e costumam ser utilizadas tanto como tratamento primário, quando recebe efluente bruto, como tratamento secundário, tratando efluentes advindos de outras unidades de tratamento. As unidades facultativas são construídas com uma profundidade que varia entre 1 e 1,5m e possuem um tempo de detenção hidráulica (TDH) alto, excedendo o tempo de 20 dias para as lagoas convencionais, e média de 10 dias para as aeradas (Pellenz, 2018). Esse tipo de sistema costuma ser utilizado em conjunto com outras lagoas de tratamento, formando sistema de estabilização, que conferem uma maior eficiência na remoção da matéria orgânica (Lucena, 2016).

Os autores Melo et al. (2018a) e Melo et al. (2018b) estudaram o comportamento da concentração de DBO e a concentração de fósforo, respectivamente, de uma lagoa facultativa aplicada no tratamento de esgoto bruto. Ambos os estudos monitoraram a lagoa facultativa por um período de três meses. No primeiro estudo, os autores puderam constatar uma remoção de DBO equivalente a $61,43 \%$ no efluente tratado durante esse período. Enquanto que no segundo estudo citado, sobre a concentração de fósforo, o índice médio de remoção de fósforo pela lagoa facultativa foi de $81,58 \%$. Ambos resultados apresentaram valores satisfatórios, e os autores concluíram que as lagoas facultativas desenvolvem um importante papel no adequado tratamento do esgoto bruto da região.

Com o intuito de avaliar o desempenho de uma estação de tratamento de esgoto composta por lagoa facultativa, Bezerra e Gonzalez (2020) acompanharam o sistema de tratamento durante nove meses. Foram coletadas cinco amostras de efluente tratado durante esse período. Após as análises dos resultados, os autores constataram que a lagoa facultativa obteve um desempenho de $57 \%$ a $78 \%$ na remoção de sólidos suspensos totais (SST), $56 \%$ a $81 \%$ para a remoção de DQ0, $60 \%$ a $85 \%$ para o nitrogênio, bem como $86 \%$ a $99 \%$ na remoção de coliformes fecais. Alguns valores obtidos foram inferiores ao esperado pela literatura, porém de maneira geral os autores concluíram que a lagoa facultativa obteve resultados satisfatórios no tratamento do esgoto, entregando um efluente com especificações dentro do estabelecido para um correto descarte.

As lagoas aeradas de mistura completa são unidades de tratamento com atividade unicamente aeróbia, aeradas de maneira mecanizada e possuem um processo de tratamento simples (Brito, 2015). Enquanto que nas lagoas facultativas e de alta taxa, a aeração é feita através dos microrganismos, nesse tipo de sistema o fornecimento de oxigênio é feito através de aeradores mecânicos, que além de fornecer oxigênio também promovem a mistura do efluente com biomassa, o que acarreta num menor tempo de detenção hidráulica, entre 5\% a 10 dias (Pellens, 2018). 0 processo de tratamento é análogo ao que ocorre nas lagoas aeróbias, onde os microrganismos aeróbios degradam a matéria orgânica na presença de oxigênio dissolvido através de processos oxidativos (Brito, 2015). As lagoas aeradas são mais complexas em termos de operação em comparação às lagoas facultativas, e mais simples quando comparadas ao sistema de lodos ativados. 0 sistema aerado possui uma eficiência de $40 \%$ a $85 \%$ na remoção de DBO, e de $30 \%$ a 70\% referente à DQO (Peitz, 2018). 0 efluente das lagoas aeradas possui uma alta concentração de sólidos, sendo necessário a instalação de uma zona de decantação, a fim de produzirem um efluente clarificado (Salles, 2019). Esse sistema costuma ser utilizado em conjunto com outras lagoas, formando o sistema denominado de lagoas de estabilização (Lucena, 2016). 
As lagoas de maturação (ou de polimento) são lagoas aeróbias com oxigênio dissolvido em todo o meio líquido (Henares, 2015). São sistemas de pós-tratamento utilizados no tratamento de efluentes previamente tratados, tendo como objetivo a remoção de organismos patogênicos advindos dos coliformes fecais, nitrogênio e fósforo (Pellenz, 2018). Possui uma eficiência em torno de 99,9\% na remoção de coliformes fecais do efluente. A combinação mais utilizada desse tipo de lagoa é em conjunto com lagoas anaeróbias e facultativas (Lucena, 2016).

Cordero et al. (2015) analisaram em seu estudo o desempenho de 25 estações de tratamento de efluentes (ETEs) que tratam esgotos domésticos, formadas por lagoas de estabilização. As lagoas analisadas eram formadas pelos seguintes sistemas: lagoas facultativas, lagoas facultativas+lagoa de maturação, lagoa anaeróbia+lagoa facultativa, reator UASB+lagoa facultativa, reator UASB+lagoa de maturação, reator UASB+lagoas de estabilização (facultativas e maturação) e reator UASB seguido por filtros anaeróbios e lagoas facultativas. Sendo o reator UASB + lagoa facultativa a configuração mais utilizada nas estações estudadas. Analisando os resultados, Cordero et al. (2015) observaram que todos os sistemas estudados apresentaram um bom desempenho na remoção de DBO, DQ0 e E. coli, com valores entre $81 \%$ e $86 \%, 67 \%$ e $76 \%$, e 1,2 e 2,5 (valores em escala logarítmica), respectivamente. A configuração que obteve uma maior eficiência na remoção desses parâmetros foi reator UASB+lagoa facultativa, com $84 \%$ para DBO, $76 \%$ para DQO e 1,9 (em log) para E. coli. Os autores concluíram que 22 ETEs tiveram uma eficiência de $80 \%$ na remoção de DBO e 18 ETEs alcançaram uma eficiência $\geq 55 \%$ na remoção de DQO, valores dentro do padrão determinado para um efluente tratado. As concentrações de E. coli presentes no efluente obtiveram variados valores, necessitando de uma configuração mais eficiente na remoção de coliformes fecais.

Os filtros biológicos são unidades de tratamento indicados para o pós tratamento de efluentes de unidades anaeróbias, devido a sua alta taxa de eficiência, fácil operação e baixo custo (Santos, 2018). São constituídos de tanques contendo um meio suporte, a qual a biomassa formada pelos microrganismos presentes no meio se adere, formando biofilmes. 0 processo de tratamento acontece através do contato do afluente com o biofilme formado, ocorrendo a eliminação do material orgânico (Menezes, 2019).

Dentre os filtros biológicos aeróbios utilizados no tratamento de efluentes, destacam-se os filtros aerados submersos e os filtros biológicos percoladores.Nos filtros aeróbios submersos (FASB) o fluxo segue um curso ascendente, garantindo que o fluxo do afluente e dos compostos presentes no meio líquido tenham a mesma direção dentro do reator (Santos, 2018). 0 meio suporte é preenchido de material poroso, ao qual se alojam os microrganismos presentes nos biofilmes. Os tanques dos filtros aerados contam com aeradores localizados na parte inferior das unidades, garantindo a aeração do meio e promovendo o tratamento do efluente através de processos aeróbios. As principais vantagens na utilização dos FASB é a pequena produção de lodo, possibilidade de cobertura dos tanques e alta concentração de biomassa, atribuindo um tratamento eficiente (Silva, 2016). Nos filtros biológicos percoladores o efluente é inserido pela parte superior do reator, geralmente em jatos, e segue um fluxo descendente até chegar em contato com a biomassa aeróbia, que se encontra alojada no meio suporte (Buarque, 2017). 0 controle da biomassa que compõe o biofilme é feito através da velocidade de escoamento do efluente, que gera uma tensão de cisalhamento provocando o desprendimento de parte da biomassa, que é descartada junto com o efluente. A aeração nesse sistema é feita de forma natural, por convecção (Martins, 2016). Dentre as principais vantagens na utilização dos filtros biológicos percoladores, destacam-se o baixo custo para implementação, fácil sistema operacional e necessidade de pouca manutenção (Menezes, 2019). Diversos tipos de materiais são utilizados no preenchimento dos meios de suporte, dentre os mais aderidos destacam-se as britas, materiais plásticos e carvão antracito (Santos, 2018). 
Sabe-se que, o que tipo de material utilizado como recheio no meio suporte dos filtros percoladores tem interferência no desempenho do tratamento, sendo vasta a lista de materiais convencionais já utilizados. Visando o estudo de materiais alternativos para esse fim, Medeiros et al. (2017) compararam a eficiência e desempenho de dois filtros biológicos percoladores feitos com materiais filtrantes alternativos. 0 primeiro utilizou rejeitos de mineração e o segundo espuma de poliuretano. Foi monitorado o tratamento do esgoto doméstico de uma residência, durante um período de 92 dias. Após esse período, foi observado a eficiência média de cada material com relação às variáveis DQO, NKT (nitrogênio total Kjeldahl), fósforo e turbidez. Para a espuma de poliuretano os valores obtidos foram 65\% para DQ0, 46\% para NKT, 7\% para fósforo, e $89 \%$ para turbidez. Enquanto que para o rejeito de mineração, obtiveram $74 \%$ para DQ0, 56\% para NKT, 7\% para fósforo e 73\% para turbidez. Os autores concluíram que os dois materiais alternativos apresentaram boa eficiência no tratamento do esgoto domiciliar, com a formação de biofilme em ambos os casos. Sendo vantajoso o uso desses materiais nos filtros devido a sua eficiência e fácil aquisição.

Com relação ao tratamento utilizando a combinação de processos aeróbios e anaeróbios, Andrade et al. (2018) estudaram a eficiência do tratamento de esgoto proveniente de uma fábrica calçadista, a partir de um sistema de reator UASB seguido de filtros aerados. 0 sistema foi monitorado durante um período de 12 meses. Os resultados mostraram-se satisfatórios com relação à remoção de DQO e SST, com percentuais de 93\% para DQO e 92\% para SST. A partir da análise desses parâmetros, os autores concluíram que o sistema estudado foi eficiente no tratamento do esgoto, entregando um efluente pronto para o correto descarte.

Seguindo o mesmo viés de estudo, Monteiro et al. (2019) avaliaram o desempenho do sistema UASB e filtro biológico percolador (FBP) em escala piloto, para o tratamento da mistura de lixiviado (5\%) com esgoto doméstico (95\%). 0 FBP foi construído com material filtrante constituído de resíduos conduítes plásticos (aparas). Os autores avaliaram as eficiências do reator UASB, do FBP e do meio suporte, a fim de obterem resultados para a eficiência média de todo o sistema. 0 estudo foi dividido em três etapas, sendo a primeira destinada ao monitoramento do reator UASB e nas duas últimas o FBP. 0 reator UASB apresentou $48 \%$ de eficiência média na remoção de DQO e $67 \%$ na remoção de DBO. Para o FBP, as eficiências médias encontradas foram de $46 \%$ para a remoção de DQO e 51\% para DBO, valores abaixo do esperado. Os autores Monteiro el al. (2019) concluíram que, o meio suporte utilizado bem como as características do filtro não permitiram uma eficiente aderência da biomassa, resultando na baixa eficiência do tratamento.

0 tratamento anaeróbio é um processo que consiste na degradação da matéria orgânica presente no efluente, onde uma pequena parcela do material orgânico é convertida em lodo e outra maior em biogás (Pauli, 2018). Esse processo ocorre na ausência de oxigênio por meio de quatro etapas bioquímicas em sucessão: hidrólise, acidogênese, acetogênese e metanogênese; cada qual efetuada por uma espécie exclusiva de microrganismos (Pompêo et al., 2015).

$\mathrm{Na}$ etapa de hidrólise, as bactérias hidrolíticas expelem enzimas que convertem o material orgânico complexo em substâncias dissolvidas de menor peso molecular (Gueri et al., 2018). Na acidogênese, as bactérias acidogênicas metabolizam as substâncias geradas na hidrólise, formando produtos mais simples, tais como ácidos graxos e hidrogênio. Logo em seguida, na acetogênese, as substâncias geradas na fase anterior são oxidadas pelas bactérias sintróficas e transformadas em substratos, os quais são utilizados pelos microrganismos metanogênicos. Por fim, na etapa de metanogênese, ocorre a formação de gás carbônico $\left(\mathrm{CO}_{2}\right)$ e do principal produto desse processo, o gás metano $\left(\mathrm{CH}_{4}\right)$ (Soares et al., 2017). 
O processo anaeróbio é utilizado no tratamento de águas residuais que contêm uma grande carga de compostos orgânicos, sendo mais econômico e eficiente quando o efluente possui alta biodegradabilidade (Pauli, 2018). Entre os principais sistemas de tratamento anaeróbio, destacam-se as lagoas anaeróbias, os tanques sépticos, filtros anaeróbios e os reatores de alta taxa. Esses sistemas podem ser utilizados individualmente ou em combinações, conforme a demanda e características do efluente (Campos, 1999).

As lagoas anaeróbias caracterizam-se pela ausência de oxigênio dissolvido e são comumente utilizadas no tratamento de efluentes que possuem grandes concentrações de material orgânico e alto teor de sólidos (Maia, 2015), mostrando-se eficiente na redução da DQO (Soldera, 2018). No processo de tratamento, os sólidos que se encontram acumulados no fundo da lagoa são degradados e convertidos em gases $\left(\mathrm{CO}_{2}\right.$ e $\left.\mathrm{CH}_{4}\right)$, por meio das bactérias anaeróbias acidogênicas e metanogênicas (Maia, 2015). Esse tipo de unidade de tratamento possui um tempo de detenção hidráulica (TDH) relativamente baixo, com períodos entre 2 a 5 dias; além disso, esse método obtém uma maior eficiência na ausência de luz e em temperaturas elevadas, devido ao aumento da atividade bacteriana sob essas condições (Campos, 1999). Para evitar que o oxigênio produzido na superfície chegue até as camadas inferiores, é importante que as lagoas anaeróbias sejam construídas com uma certa profundidade (entre 3,0 e 4,5 m) (Silva, 2015). Uma das problemáticas envolvendo esse método de tratamento é o mau odor proveniente dos gases gerados, sendo necessário que essas unidades se estabeleçam em zonas afastadas das comunidades (Soldera, 2018).

Grandes concentrações de sólidos orgânicos acumulados no fundo da lagoa anaeróbia podem gerar um leito de biomassa estacionário, dificultando a interação biomassa e esgoto, o que ocasiona baixa eficiência na remoção de DBO total. Dessa forma, esse tipo de unidade de tratamento costuma ser empregado em conjunto com outros tipos de lagoas, principalmente as facultativas, formando um sistema denominado lagoas de estabilização (Campos, 1999).

Com o intuito de estudar o tratamento do lodo oriundo de fossa e tanque séptico (LFTS), Carrilho e Carvalho (2016) avaliaram os efeitos da disposição desse lodo em lagoas de estabilização. 0 sistema estudado pelos autores é composto por dois módulos, cada um formado por uma lagoa anaeróbia em combinação com lagoa facultativa. 0 módulo I atuou como grupo controle e o módulo II como receptor de LFTS. A unidade anaeróbia receptora do efluente recebeu diferentes taxas de aplicação de lodo $(13 \%$ a $204 \%$ ), durante um período de seis meses. Os resultados obtidos indicaram que o efluente do módulo II apresentou valores de concentração de 1,8, 2,0 e 9,0 vezes superior em comparação ao módulo de controle, para o fósforo, nitrogênio amoniacal e E. coli, respectivamente. Houve também um aumento do lodo sedimentado na lagoa anaeróbia do grupo receptor e uma maior formação de escuma. Apesar do aumento dos compostos orgânicos e do acúmulo de lodo nas lagoas do módulo II, o processo final de tratamento do efluente não foi prejudicado. Dessa forma, os autores concluíram que as lagoas de estabilização, mais especificamente a combinação de lagoa anaeróbia e lagoa facultativa, são uma alternativa satisfatória para o tratamento dos tanques e fossas sépticas.

Com relação ao tratamento de efluentes a partir da combinação de métodos aeróbios e anaeróbios, Maia et al. (2015) analisaram o desempenho de um sistema biológico para o tratamento de lixiviado oriundo de um aterro sanitário. Os autores estudaram um sistema em escala real que utiliza a combinação de diferentes métodos de tratamento, sendo formado por duas lagoas anaeróbias operadas em série, um sistema de lodos ativados e uma lagoa facultativa. O monitoramento da unidade de tratamento biológico ocorreu durante um período de 16 meses. A eficiência na remoção da matéria orgânica e diminuição do $\mathrm{DQO}$ e $\mathrm{DBO}_{5}$ no efluente tratado foi de $80 \%, 60 \%$ e $85 \%$, respectivamente. Também foram obtidos resultados satisfatórios com relação à remoção de nitrogênio amoniacal e fósforo, com valores de $83 \%$ e $73 \%$, respectivamente. 
Observou-se também uma diminuição de 44\% no índice de toxicidade do efluente tratado, sendo um valor abaixo do esperado. Maia et al. (2015) concluíram que a configuração do sistema de tratamento biológico apresentou resultados satisfatórios na remoção da matéria orgânica e fração nitrogenada, contudo não foi eficiente na diminuição da toxicidade, havendo assim a necessidade de um tratamento complementar para um correto descarte do lixiviado.

Sabendo que o grau de biodegradabilidade do lixiviado é fortemente caracterizado a partir da relação DBO/DQO, Baettker et al. (2018) avaliaram o comportamento do decaimento da matéria orgânica de lixiviados tratados em lagoas anaeróbias, a partir do tempo de detenção (td) esperado para se obter uma eficiência de 50\% na remoção da DBO. No estudo, a metodologia empregada consistia na observação de um tanque com $7.500 \mathrm{~L}$ (lagoa anaeróbia) monitorado a cada 15 dias, durante o período de um ano. Foram coletadas quatro amostras durante esse tempo. Os autores constataram que para as quatro amostras coletadas, o decaimento da DBO atingiu eficiência de $50 \%$ em um período de 30 a 120 dias, enquanto que para a DQO o tempo de detenção para atingir a mesma eficiência foi de 90 a 120 dias. Os resultados obtidos foram convergentes com os resultados breves da literatura, apresentando um tempo de detenção abaixo do esperado.

Os tanques sépticos são unidades de tratamento primário que operam via sedimentação e digestão anaeróbia (Silva, 2018). Costumam ser empregados em áreas desprovidas de rede coletora de esgoto, por possuir um baixo custo de implantação e apresentar uma grande eficiência no tratamento de efluentes domésticos (Pompêo et al., 2015). 0 processo de tratamento ocorre primeiramente via sedimentação, onde a maior parte da carga sólida é degradada, gerando lodo. 0 restante não processado, chamado de escuma, se estabelece na superfície do líquido. As bactérias anaeróbias são responsáveis pela última fase do tratamento, digerindo o lodo e a escuma (Campos, 1999). Esse método apresenta baixa eficiência na remoção da DBO solúvel e considerável geração de lodo, sendo necessária a combinação com outra unidade de tratamento, geralmente filtros anaeróbios, para que ocorra um correto descarte do efluente (Silva, 2018).

Buscando alternativas para um correto tratamento de esgoto sanitário em comunidades rurais, Postigo et al. (2017) analisaram a eficiência de uma fossa séptica destinada ao saneamento rural. A fossa séptica foi construída com operação e funcionamento semelhante a um tanque séptico, sendo uma alternativa de baixo custo para o tratamento do efluente em questão. As amostras foram coletadas após 60 dias de instalação da fossa. Analisando os dados obtidos, os autores constataram que houve uma remoção de 47,61\% da matéria orgânica, com base no valor da $\mathrm{DBO}_{5}$. Em relação ao teor de sólidos totais, o tratamento obteve uma redução de 69,30\%. Não foi observado mudança nos valores de $\mathrm{pH}$. Também foram encontrados vestígios de coliformes fecais nas amostras, visto que o efluente provinha de esgotos sanitários. Os resultados obtidos foram inferiores aos padrões impostos pela legislação ambiental vigente, no que diz respeito ao tratamento e descarte de efluentes em corpos hídricos. Dessa forma, os autores concluíram que as fossas sépticas apresentam-se como uma solução promissora no tratamento de esgotos em áreas rurais, contudo, é necessário um maior estudo para obter um tratamento mais eficaz e correto descarte do efluente.

0 filtro anaeróbio consiste em um tanque biológico, que pode apresentar fluxo ascendente ou descendente e é constituído por dois compartimentos, um localizado na parte superior, preenchido com elementos filtrantes que permitem o alojamento dos microrganismos degradantes, e outro na parte inferior, que tem a função de reter o lodo produzido durante o processo (Backes, 2016). O processo de tratamento nesse tipo de unidade ocorre por meio do contato direto do efluente com os microrganismos anaeróbios alojados no material filtrante, promovendo a conversão da matéria orgânica em biogás (Baettker, 2015). Esse tipo de reator costuma ser empregado no pós-tratamento de outras 
unidades anaeróbias, devido a sua eficiência na remoção do material orgânico dissolvido, produção de pouco lodo e por não consumir energia elétrica (Backes, 2016).

Visando a analisar comparativamente a eficiência do emprego de filtros anaeróbios no tratamento de efluente de tanque séptico, Fernandes et al. (2015) propuseram três filtros anaeróbios preenchidos com diferentes materiais filtrantes. 0 primeiro filtro foi preenchido com a bucha vegetal Luffa cylindrica, o segundo com aparas de eletroduto corrugado e o terceiro com brita granítica. A remoção de $\mathrm{DQO}_{\text {e }} \mathrm{DBO}_{5}$ apresentaram resultados satisfatórios, com valores de $\mathrm{DBO}_{5}$ entre $22 \%$ e $57 \%$ para os dois primeiros filtros e variação de $48 \%$ a $84 \%$ no terceiro filtro. Para a remoção de DQO foram encontrados valores entre $33 \%$ e $55 \%$ no filtro $1,23 \%$ e $45 \%$ no filtro 2 , bem como $30 \%$ a $52 \%$ no filtro 3. Os diferentes tipos de materiais filtrantes mostraram-se eficientes na remoção da carga orgânica do efluente advindo do tanque séptico, sendo a bucha vegetal um promissor substituto para os materiais de filtração convencionais, devido ao seu baixo custo e fácil acesso.

Ainda sobre os diferentes tipos de materiais utilizados como recheio nos filtros anaeróbios, Baettker et al. (2018) avaliaram o comportamento do uso de filtros anaeróbios no tratamento de esgoto sanitário sintético. No presente estudo, foram comparados três filtros preenchidos com diferentes materiais filtrantes, sendo esses o carvão ativado, cerâmica de argila e borracha de pneu. As unidades foram operadas em duas etapas, com tempo de detenção hidráulica de oito e quatro horas, de modo que todos os filtros obtiveram desempenho satisfatório nas duas etapas de operação. Com relação aos valores de remoção de DQO, o filtro preenchido com carvão ativado apresentou melhores resultados com $94 \%$ e $81 \%$ nas etapas 1 e 2 , respectivamente, em seguida veio o filtro com borracha, com valores de $88 \%$ e $63 \%$, seguido do filtro com cerâmica de argila com $81 \%$ e $61 \%$, ambos para a etapa 1 e 2 , respectivamente. A diferença encontrada entre os filtros é devido às características intrínsecas a cada material utilizado no preenchimento.

Seguindo o mesmo viés de estudo sobre o uso de filtros anaeróbios no pós tratamento de efluentes de outras unidades, Silva et al. (2018) analisaram o desempenho de um filtro anaeróbio de fluxo ascendente no tratamento de efluente de suinocultura proveniente de reator anaeróbio. Foram realizadas análises físico-químicas nas amostras do afluente e efluente do filtro anaeróbio. Dentre os resultados mais importantes para determinar a eficiência do método de tratamento, destacam-se os valores obtidos na remoção da $\mathrm{DBO}_{5}$, com 72,14\%, da DQ0 total e filtrada com 67,08 e 70,57\%, respectivamente, e na remoção de nitrogênio total, com 33,1\%. Para os sólidos totais, fixos e voláteis foram encontrados valores de remoção de 29,9\%, 21,5\% e 37,4\%, respectivamente. Com base nas análises físicas e químicas, os autores Silva et al. (2018) apontaram a eficiência e importância da combinação de reator anaeróbio e filtro anaeróbio no tratamento de rejeitos animais.

Os reatores anaeróbios de alta taxa são comumente utilizados no tratamento de efluentes que possuem uma grande quantidade de carga orgânica, operando com um menor tempo de detenção hidráulica (TDH) e um maior tempo de retenção celular (TRC). Dentre as principais unidades pertencentes a esse grupo de reatores, destaca-se o reator anaeróbio de manta de lodo (UASB) (Campos, 1999). 0 reator anaeróbio de manta de lodo consiste em uma coluna de escoamento com fluxo ascendente e é composto por três setores que constituem o processo de tratamento, uma zona de digestão, uma de sedimentação e um setor de separação de fases (Neves et al., 2019). A degradação da matéria orgânica nessa unidade ocorre no setor de digestão, onde o material orgânico é misturado ao lodo e digerido pelos microrganismos anaeróbios, produzindo biogás e aumento da massa microbiana. $O$ efluente segue um curso ascendente, passando pelo separador de fases e sendo despejado do reator no setor de sedimentação, previamente tratado e sem vestígios sólidos (Cabral, 2016). O reator UASB é um dos métodos 
anaeróbios mais utilizados no tratamento de efluentes, pois sua configuração permite o tratamento de altos volumes com um curto tempo de detenção hidráulica (Rodrigues et al., 2016).

Com relação a remoção de matéria orgânica, sólidos e nutrientes, Nunes et al. (2019), objetivaram em seu estudo tratar esgotos domésticos através do reator anaeróbio de fluxo ascendente com manta de lodo (UASB), seguido de filtro biológico percolador (FBP). Os sistemas experimentais foram construídos em forma de bancada, o reator UASB tratou durante oito horas diárias aproximadamente $10 \mathrm{~L}$ de esgoto. Já o FBP, composto com três camadas diferentes, uma de areia e duas de brita, tratou cerca de $6 \mathrm{~L}$ de esgoto por dia. Os resultados mostraram a eficiência do reator UASB em 66,55\%, equivalente à remoção da matéria orgânica; já o valor médio de eficiência obtido para remoção da matéria orgânica no FBP foi de $62 \mathrm{mgO}_{2} / \mathrm{L}$. Embora a conclusão tenha identificado que há necessidade de melhorias na remoção de sólidos do efluente final, os autores destacaram a importância da combinação de sistemas anaeróbio-aeróbio, sendo a combinação entre reator UASB e o FBP alternativas promissoras no tratamento de esgotos domésticos comparados ao método convencional, uma vez que permitem um baixo custo de implantação e produzem efluentes de boa qualidade. Divergindo com o estudo de Monteiro et al. (2019), onde o FBP não apresentou resultados satisfatórios, devido ao tipo do material filtrante utilizado.

Ainda com o intuito de analisar a remoção de matéria orgânica dos efluentes, a partir da combinação de métodos anaeróbios e aeróbios, Rodrigues et al. (2016) em seu estudo avaliaram o desempenho do sistema reator UASB-Filtro anaeróbio no tratamento de efluentes de abate de frangos. Compuseram esse sistema: a peneira estática, caixa de gordura, reator UASB e filtro anaeróbio. Foram avaliados como variáveis de desfecho a temperatura, $\mathrm{pH}, \mathrm{DQO}, \mathrm{DBO}$, sólidos suspensos totais (SST) e sólidos suspensos voláteis (SSV). A remoção do sistema para DBO mostrou eficiência variada de $83 \%$ a 99\%, e para DQO de 50\% a 98\%. A eficiência de remoção média de SST e SSV foi de $92 \%$. 0 estudo concluiu que o sistema reator UASB seguido de filtro anaeróbio apresentou alto desempenho na remoção dos resíduos orgânicos, sendo uma boa opção para o tratamento de águas residuárias.

\section{Conclusão}

Diante da revisão de literatura realizada e com base nos dados discutidos, nota-se que ambos os métodos de tratamento biológico, aeróbio e anaeróbio, têm apresentado resultados satisfatórios. Sendo que, as maiores eficiências no tratamento de efluentes foram evidenciadas nos sistemas em que os dois processos atuaram em conjunto.

Com relação aos métodos aeróbios, o sistema de lodos ativados tem sido relatado na literatura como o de maior desempenho no que diz respeito à remoção da carga orgânica, atingindo valores de até $95 \%$ de eficiência. Quando utilizado como unidade de pós tratamento, seu maior desempenho acontece no sistema em conjunto com o reator UASB. No contexto das lagoas aeróbias, as lagoas facultativas foram relatadas como a de maior desempenho, quando avaliado o tratamento aeróbio aplicado a esgotos. Segundo dados da literatura, as lagoas aeróbias atingem um maior potencial de tratamento quando inseridas no sistema de lagoas de estabilização, atuando de maneira satisfatória na remoção de nutrientes do efluente final. Os filtros aeróbios são frequentemente empregados como unidades de pós tratamento, principalmente integrados a reatores UASB. Seu desempenho está diretamente relacionado ao tipo de material filtrante inserido no meio suporte, o que fomenta diversas pesquisas sobre o uso de materiais filtrantes alternativos. Para o filtro biológico percolador, o uso de rejeitos de mineração como material filtrante tem apresentado resultados satisfatórios na remoção de DBO e DQO do efluente. 
Dentre os métodos anaeróbios de tratamento, o Reator anaeróbio de manta de lodo com fluxo ascendente (UASB) tem sido relatado como o mais eficiente quando utilizado em conjunto com outras unidades de pós tratamento, isso deve ao fato de que o reator possui uma grande capacidade volumétrica, efetuando o tratamento de grandes volumes de efluente com reduzido tempo de detenção hidráulica, além de apresentar bom desempenho na remoção da carga orgânica. Com relação ao tratamento de efluentes domésticos, os tanques sépticos ou fossas sépticas são os mais utilizados, por apresentar baixo custo de implantação e fácil operação, porém estudos indicam que ainda há a necessidade de um pós-tratamento de seus efluentes, devido a baixa eficiência na remoção de resíduos orgânicos. Os filtros anaeróbios também apresentam alto desempenho quando utilizados como sistemas de pós tratamento integrado a outros métodos anaeróbios, por apresentar alta eficiência na remoção da carga orgânica dissolvida e produção de pouco lodo. Com relação aos materiais filtrantes utilizados no meio suporte, estudos apontam a bucha vegetal Luffa cylindrica como um material alternativo promissor, apresentando resultados satisfatórios, além de possuir um baixo custo. Segundo os dados analisados, as lagoas anaeróbias mostram-se eficazes na remoção de sólidos orgânicos, podendo ser utilizadas como um sistema de tratamento primário ou em conjunto com lagoas fotossintéticas.

\section{Conflito de interesses}

Os autores declaram não haver conflito de interesses.

\section{Referências}

Andrade, M. V. F.; Silva, D. H.; Gomes, F. B. M.; Costa, M. C. Avaliação da eficiência de estação de tratamento de esgoto em indústria no Município de Sobral-CE. Anais do XIV Simpósio Ítalo-Brasileiro de Engenharia Sanitária e Ambiental, Foz do Iguaçu, 2018.

Azevedo, P. G. F.; Oliveira, D. C. S.; Cavalcanti, L. A. P. Processos físicos e químicos para o tratamento de efluentes: uma revisão integrativa. Revista Brasileira de Gestão Ambiental e Sustentabilidade, v. 7, n.17, p.1667-1678, 2020. https://doi.org/ 10.21438/rbgas(2020)071740

Aziz, A.; Basheer, F.; Sengar, A.; Irfanullah; Khan, S. U.; Farooqi, I. H. Biological wastewater treatment (anaerobic-aerobic) technologies for safe discharge of treated slaughterhouse and meat processing wastewater. Sciente of the Total Environment, v. 686, p. 681-708, 2019. https://doi.org/10.1016/j.scitotenv.2019.05.295

Backes, F. J. Avaliação da eficiência de um sistema de fossa séptica e filtro anaeróbio em escala piloto para o tratamento de efluente sanitário com a adição de papel higiênico como fonte de matéria orgânica. Lajeado: Centro Universitário Univates, 2016. (Trabalho de conclusão de curso).

Baettker, E. C. Avaliação do desempenho de filtros anaeróbios preenchidos com diferentes meios suportes no tratamento de água residuária sintética. Curitiba: Universidade Tecnológica Federal do Paraná, 2015. (Dissertação de mestrado).

Baettker, E. C.; Carvalho, K. Q.; Freire, F. B.; Passig, F. H.; Morais, J. L. Materiais alternativos como meio suporte de filtros anaeróbios para o tratamento de esgoto sanitário sintético. Engenharia Sanitária e Ambiental, v. 23, n. 6, p. 1091-1102, 2018. https://doi.org/ 10.1590/S1413-41522018170758 
Baettker, E. C.; Rietow, J. C.; Aisse, M. M. Avaliação do decaimento da matéria orgânica de lixiviados de aterros sanitários em lagoas anaeróbias. Anais do XIV Simpósio ÍtaloBrasileiro de Engenharia Sanitária e Ambiental, Foz do Iguaçu, 2018.

Baréa, P. B.; Azevedo, B. R.; Ross, B. Z. L.; Pessotto, B.; Aisse, M. M. Avaliação de desempenho de um sistema reator anaeróbio de manta de lodo modificado integrado a processo de lodo ativado tratando esgoto sanitário. Anais do $30^{\circ}$ Congresso Nacional de Saneamento e Meio Ambiente, 2019. Disponível em: <https://tratamentodeagua.com.br/ wp-content/uploads/2019/11/reator-anaerobio-manto-lodo-ativado.pdf>. Acesso em: 02 mar. 2021.

Bezerra, Y. A. F.; Gonzalez, B. C. Avaliação da eficiência da estação de tratamento de esgoto do Município de Campina do Monte Alegre. Revista Científica ANAP Brasil, v. 13, p. 120-124, 2020. https://doi.org/10.17271/19843240133020202610

Brasil. Resolução CONAMA no 430, de 13 de maio de 2011. Dispõe sobre as condições e padrões de lançamento de efluentes, complementa e altera a Resolução no 357, de 17 de março de 2005, do Conselho Nacional do Meio Ambiente - CONAMA. Disponível em: <http://www.mma.gov.br/port/conama/legiabre.cfm?codlegi=646>. Acesso em: 13 mar. 2021.

Brito, L. F.; Silva, L. F. A.; Silva, G. S.; Lima, S. F. Tratamento de esgoto sanitário por meio do uso de lagoas aeradas. Ciências Exatas e Tecnológicas, v. 3, p. 165-176, 2015.

Buarque, P. M. C. Avaliação da remoção de micropoluentes emergentes e nitrogênio em sistemas anaeróbios e microaeróbios seguidos de filtros biológicos percoladores sujeitos à aeração natural e forçada. Fortaleza: Universidade Federal do Ceará, 2017. (Tese de doutorado).

Cabral, C. B. G. Avaliação da produção de biogás para fins energéticos em reatores anaeróbios tratando esgoto sanitário. Florianópolis: Universidade Federal de Santa Catarina, 2016. (Dissertação de mestrado).

Campos, J. R. (Coord.). Tratamento de esgotos sanitários por processo anaeróbio e disposição controlada no solo. Rio de Janeiro: ABES, 1999. (Projeto PROSAB).

Carrilho, S. M. A. V.; Carvalho, E. H. Avaliação da disposição de lodos de fossa e tanque séptico em lagoas de estabilização que tratam lixiviados de aterro sanitário. Engenharia Sanitária e Ambiental, Vol. 21, n. 1, p. 183-196, 2016. https://doi.org/10.1590/S141341520201600100136031

Carvalho, R. P. J. Avaliação da eficiência do sistema de lagoas de alta taxa como póstratamento dos reatores UASB para garantia da qualidade do efluente final - ETE Paranoá/DF. Brasília: Universidade de Brasília, 2018. (Monografia de graduação).

Cordero, M. F. E.; Albuquerque, P.; Von Sperling, M.; Freire, A. Avaliação do desempenho de lagoas de estabilização em escala real no Estado de Minas Gerais. Anais do $28^{\circ}$ Congresso Brasileiro de Engenharia Sanitária e Ambiental, Rio de Janeiro, 2015.

Cornelli, R.; Amaral, F. G.; Danilevicz, A. M. F.; Guimarães, L. B. M. Métodos de tratamento de esgotos domésticos: uma revisão sistemática. Revista de Estudos Ambientais, v. 16, p. 20-36, 2014. https://doi.org/10.7867/1983-1501.2014v16n2p20-36

Fernandes, W. V.; Athayde, G. B. J.; Batista, M. M.; Anjos, R. H. J. Avaliação da remoção de matéria orgânica de efluente de tanque séptico utilizando filtro anaeróbio preenchido com Luffa cylindrica como meio suporte. Revista Eletrônica de Gestão e Tecnologias Ambientais, v. 3, n. 1, p. 1-13, 2015. 
Ferreira, M. M.; Seibert, M. R. Balanços de massa e energia para uma estação de tratamento de esgoto sanitário composta por UASB, lagoa de alta taxa e sistema de separação de algas. Vitória: Universidade Federal do Espírito Santo, 2016. (Trabalho de Conclusão de Curso).

Gehling, G. Lagoas de estabilização. In: Gehling, G. Tratamento de água e esgoto. Porto Alegre: Universidade Federal do Rio Grande do Sul, 2017. p. 97-194.

Guedes, C. D. A presença de fármacos nos esgotos domésticos e sua remoção pelos processos de lodo ativado com oxigênio puro, lagoa aerada e reator anaeróbio de fluxo ascendente. São Paulo: Universidade de São Paulo, 2017. (Tese de doutorado).

Gueri, M. V. D.; Souza, S. N. M.; Kuczman, O. Parâmetros operacionais do processo de digestão anaeróbia de resíduos alimentares: uma revisão. Biofix Scientific Journal, v. 3, n. 1, p. 17-25, 2018. https://doi.org/10.5380/biofix.v3i1.55837

Henares, J. F. Caracterização do efluente de laticínio: análise e proposta de tratamento. Campo Mourão: Universidade Tecnológica Federal do Paraná, 2015. (Trabalho de conclusão de curso).

Iopp, P. L.; Mendes, A. T. Análise de sistemas de tratamento de efluentes de abatedouros bovinos por lagoas de estabilização e por reator UASB seguido de lagoa de polimento. Revista AIDIS de Ingeniería y Ciencias Ambientales: Investigación, Desarrollo y Práctica, v. 13, p. 640-654, 2020. https://doi.org/10.22201/iingen.0718378xe.2020. 13.2.68142

Lucena, D. V. Avaliação do desempenho de lagoas de polimento em fluxo contínuo e semincontínuo no pós-tratamento de efluentes de reator UASB. Campina Grande: Universidade Estadual da Paraíba, 2016. (Trabalho de conclusão de curso).

Maia, I. S. Avaliação de lagoas anaeróbias em escala real no tratamento de lixiviados: estudo de caso. Florianópolis: Universidade Federal de Santa Catarina, 2015. (Tese de doutorado).

Maia, I. S.; Restrepo, J. J. B.; Castilhos, A. B. J.; Franco, D. Avaliação do tratamento biológico de lixiviado de aterro sanitário em escala real na Região Sul do Brasil. Engenharia Sanitária e Ambiental, v. 20, n. 4, p. 665-675, 2015. https://doi.org/10.1590/S141341522015020040140926

Marcon, A. L. S. Eficiência no tratamento e controle de efluentes de uma indústria de bebidas. Cuiabá: Universidade Federal de Mato Grosso, 2018. (Monografia de especialização).

Martins, V. F. Influência do meio suporte e da presença de vegetação no desempenho de filtros biológicos percoladores. Viçosa: Universidade Federal de Viçosa, 2016. (Dissertação Magister Scientiae).

Mata, $R$, A. Efeitos do lixiviado de cinzas de precipitadores eletrostáticos de caldeiras de recuperação no tratamento biológico de efluentes de indústrias de polpa celulósica kraft. Viçosa: Universidade Federal de Viçosa, 2016. (Dissertação de mestrado). 
Medeiros, R. C.; Fagundes, B. R.; Cardozo, B.; Costa, C. M.; Volpatto, F. Utilização de rejeitos como meio filtrante em filtros biológicos percoladores. Anais do VIII Congresso Brasileiro de Gestão Ambiental, Campo Grande, 2017.

Melo, A. S. J.; Bento, R. C. F.; Papadopoli, G. U.; Morais, A. C.; Hock, L. B. J.; Chirinos, G. J. Avaliação da demanda bioquímica de oxigênio (DBO) em uma lagoa facultativa. INOVAEJournal of Engineering, Architecture and Technology Innovation, v. 6, p. 300-319, 2018a.

Melo, A. S. J.; Ribeiro, K. A.; Merij, A. C.; Lima, A. L.; Tavares, G. R.; Riquelme, J. P. M. Concentração de fósforo total em sistema alternativo de tratamento por lagoa facultativa. INOVAE - Journal of Engineering, Architecture and Technology Innovation, v. 6, p. 172-190, 2018b.

Menezes, R. O. A influência da recuperação no processo anammox em um filtro biológico percolador utilizando espumas de poliuretano como meio suporte. Campinas: Universidade Estadual de Campinas, 2019. (Dissertação de mestrado).

Monteiro, M. M.; Baréa, P. B.; Cubas, S. A.; Aisse, M. M. Filtro biológico percolador como pós-tratamento de efluentes anaeróbios: Uma reflexão. Anais do $30^{\circ}$ Congresso Brasileiro de Engenharia Sanitária e Ambiental, 2019.

Neves, A. P. N.; Ferreira, D. S.; Castro, D. A.; Cavallini, G. S. Avaliação da eficiência de remoção de matéria orgânica em efluente sanitário em função da idade do lodo de reator UASB: um estudo de caso. Journal of Biotechnology and Biodiversity, v. 7, p. 449-456, 2019. https://doi.org/10.20873/jbb.uft.cemaf.v7n4.neves

Nunes, I. H.; Silva, L. S. M.; Sousa, K. A.; Sousa, C.; Sousa, J. T. Utilização de reator UASB seguido de filtro biológico percolador no tratamento de esgoto doméstico. Anais do $30^{\circ}$ Congresso Brasileiro de Engenharia Sanitária e Ambiental, 2019.

Pauli, A. R. Tratamento em duas fases na purificação de efluentes de lixiviados pela integração dos processos de eletrocoagulação e oxidação biológica. Toledo: Universidade Estadual do Oeste do Paraná, 2018. (Tese de doutorado).

Peitz, C. Desempenho de sistema modificado de lagoa aerada com meio de suporte em leito móvel no tratamento de efluente de celulose kraft. Curitiba: Universidade Tecnológica Federal do Paraná, 2018. (Dissertação de mestrado).

Pellenz, A. H. Avaliação da eficiência de lagoas de estabilização no pós-tratamento de efluentes industriais: estudo de caso. Porto Alegre: Universidade Federal do Rio Grande do Sul, 2018. (Trabalho de conclusão de curso).

Pereira, V. G. Avaliação de metais em efluente e lodo de esgoto doméstico de um sistema de lagoas aeradas de São João da Boa Vista utilizando a técnica SR-TXRF. Campinas: Universidade Estadual de Campinas, 2015. (Dissertação de mestrado).

Pompêo, M.; Carlos, V. M.; Nishimura, P. Y.; Silva, S. C.; Doval, J. C. L. Ecologia de reservatórios e interfaces. São Paulo: Instituto de Biociências da Universidade de São Paulo, 2015.

Postigo, M. D.; Bressane, A.; Franceschini, G.; Chaves, M. R. M.; Longo, R. M. Avaliação da eficiência de fossa séptica de baixo custo desenvolvida para o saneamento rural. Engenharia Ambiental, v. 14, n. 1, p. 26-35, 2017. 
Rocha, C. M.; Machado, K. S. C.; Andrade, L. H.; Brandt, E. M. F. Dimensionamento e comparação de estações de tratamento de efluentes utilizando lodos ativados e reator UASB para uma cervejaria artesanal. Revista Processos Químicos, v. 11, n. 22, p. 83-85, 2017. https://doi.org/10.19142/rpq.v11i22.411

Rodrigues, L. S.; Lopes, B. C.; Lima, C. A.; Ribeiro, M. C.; Santos, R. P.; Silva, I. J. Tratamento de efluentes de abatedouro de frangos por meio de reator UASB seguido de filtro anaeróbio. Arquivo Brasileiro de Medicina Veterinária e Zootecnia, v. 68, n. 1, p. 97-103, 2016. https://doi.org/10.1590/1678-4162-7809

Salles, N. A. Cotratamento de esgoto sanitário e lixiviado de aterro sanitário em sistemas de lagoas aeradas e de lodos ativados: abordagem utilizando o ASM. São Paulo: Escola Politécnica da Universidade de São Paulo, 2019. (Dissertação de mestrado).

Santos, A. S.; Almeida, J. N.; Pegoretti, H. M.; Soares, G. B.; Viroli, S. L. M. Avaliação do tratamento de efluentes em uma indústria frigorífica de abate bovino. Anais da 7aㅡ Jornada de Iniciação Científica e Extensão do Instituto Federal do Tocantins, Palmas, 2016.

Santos, J. V. T. S. Avaliação do desempenho de filtro biológico como pós-tratamento de reator combinado anaeróbio-aeróbio de leito fixo visando ao reuso de esgoto sanitário. Delmiro Gouveia: Universidade Federal de Alagoas, 2018. (Trabalho de conclusão de curso).

Silva, J. R. M.; Fia, F. R. L.; Campos, C. M. M.; Fia, R.; Oliveira, L. F. C. Avaliação hidrodinâmica de dois reatores UASB e um filtro biológico aerado submerso. Anais do $28^{\circ}$ Congresso Brasileiro de Engenharia Sanitária e Ambiental, Rio de Janeiro, 2015.

Silva, J. S. Remoção de matéria orgânica em tanque séptico com biomassa aderida. Londrina: Universidade Tecnológica Federal do Paraná, 2018. (Dissertação de mestrado).

Silva, P. C.; Campos, C. M. M. Desempenho de um filtro anaeróbio de fluxo ascendente como unidade de tratamento para efluente de suinocultura. Ambiência, v. 14, n. 3, p. 561-578, 2018. https://doi.org/10.5935/ambiencia.2018.03.10

Silva, T. M. R. Aplicação de sistema combinado por filtro anaeróbio seguido de biofiltro aerado submerso ao tratamento de esgotos sanitários de unidades residenciais unifamiliares. Brasília: Universidade de Brasília, 2016. (Dissertação de mestrado).

Silva, V. E. M. Tratamento de efluentes vinícolas por processos biológicos. Vila Real: Universidade de Trás-os-Montes e Alto Douro, 2015. (Dissertação de mestrado).

Soares, C. M. T.; Feiden, A.; Tavares, S. G. Fatores que influenciam o processo de digestão anaeróbia na produção de biogás. NATIVA - Pesquisas Agrárias e Ambientais, v. 5, p. 509-514, 2017. https://doi.org/10.5935/2318-7670.v05nespa10

Soldera, P. E. S. Parâmetros para o projeto de lagoas anaeróbias para tratamento de efluentes de abatedouros de bovinos. Limeira: Universidade Estadual de Campinas, 2018. (Tese de doutorado).

Sousa, N. T. M.; Paz, G. J. J.; Matsumoto, T. Análise da viabilidade técnico-econômica na implantação de aeradores superficiais para ampliação da capacidade de tratamento em lagoas facultativas. Anais do $29^{\circ}$ Congresso Nacional de Saneamento e Meio Ambiente, 2018. 
Von Sperling, M. Princípios do tratamento biológico de águas residuárias: lodos ativados. 4. ed. Belo Horizonte: Editora UFMG, 2016.

Informação da Licença: Este é um artigo Open Access distribuído sob os termos da Licença Creative Commons Attribution, que permite uso irrestrito, distribuição e reprodução em qualquer meio, desde que a obra original seja devidamente citada. 